University of Nebraska - Lincoln

DigitalCommons@University of Nebraska - Lincoln

1997

\title{
Oviposition pheromone in the Simulium damnosum complex: biological activity of chemical fractions from gravid ovaries
}

\author{
P. J. McCall \\ Liverpool School of Tropical Medicine \\ R. R. Heath \\ USDA-ARS
}

B. D. Dueben

USDA-ARS

M. D. Wilson

University of Ghana

Follow this and additional works at: https://digitalcommons.unl.edu/entomologyother

Part of the Entomology Commons

McCall, P. J.; Heath, R. R.; Dueben, B. D.; and Wilson, M. D., "Oviposition pheromone in the Simulium damnosum complex: biological activity of chemical fractions from gravid ovaries" (1997). Entomology Papers from Other Sources. 16.

https://digitalcommons.unl.edu/entomologyother/16

This Article is brought to you for free and open access by the Entomology Collections, Miscellaneous at DigitalCommons@University of Nebraska - Lincoln. It has been accepted for inclusion in Entomology Papers from Other Sources by an authorized administrator of DigitalCommons@University of Nebraska - Lincoln. 


\title{
Oviposition pheromone in the Simulium damnosum complex: biological activity of chemical fractions from gravid ovaries
}

\author{
P. J. MCCALL, ${ }^{1}$ R. R. HEATH, ${ }^{2}$ B. D. DUEBEN ${ }^{2}$ and M. D. WILSON ${ }^{3}$ \\ 'Division of Parasite and Vector Biology, Liverpool School of Tropical Medicine, Liverpool, U.K., \\ ${ }^{2}$ Center for Medical, Agricultural and Veterinary Entomology, USDA/ ARS, Gainesville, Florida, U.S.A., \\ and ${ }^{3}$ Noguchi Memorial Institute for Medical Research, University of Ghana, Legon, Accra, Ghana
}

\begin{abstract}
Communal oviposition in the Afrotropical blackfly species complex Simulium damnosum Theobald (Diptera: Simuliidae) is mediated by a pheromone emitted by freshly laid eggs. Previously, two compounds (designated peaks $A$ and $B$ ) emanating from fresh eggs were shown to be associated with attractiveness to gravid blackflies in bioassay. The present study investigated the role of these compounds by testing the responses of wild-caught Simulium yahense in Ghana to fractionated hexane extracts of gravid ovaries prepared by gas chromatography (GC). Although the fractions were prepared from Sierra Leonean Simulium leonense, GC analysis of the emissions from fresh S.yahense eggs showed that the volatile blends of both species were similar. When tested in a two-choice bioassay, $66 \%$ of ovipositing blackflies chose the substrate baited with a mixture of the four fractions recombined. In a series of bioassays testing responses to the four individual fractions presented with a control in a multiple-choice arrangement, only fraction 3 (containing peaks $A$ and $B$ ) attracted significantly more ovipositions than the other fractions and control. However, fraction 3 failed to elicit a significant response when presented as the sole attractant with a control in a two-choice bioassay. It was concluded that fraction 3, though mainly responsible for mediating aggregated oviposition by S.yahense, was acting in tandem with additional cues, probably further chemicals, which remain to be isolated and characterized.
\end{abstract}

Key words. Simulium damnosum, blackfly, bioassay, aggregation pheromone, semiochemical, oviposition, onchocerciasis.

\section{Introduction}

Afrotropical blackflies (Diptera: Simuliidae) of the Simulium domnosum Theobald complex oviposit communally, with individual females depositing their eggs in batches within aggregations. These aggregations can be produced by large numbers of flies ovipositing during limited time periods onto single substrates. The behaviour has also been observed in a number of other blackfly species (Crosskey, 1990), and in S.damnosum s.l. it was shown to be mediated by a pheromone emitted by the first eggs laid onto the substrate (McCall et al., 1994; McCall, 1995). Working with S.leonense in Sierra Leone, McCall (1995) showed that

Correspondence: Dr P. J. McCall, Tropical Parasitic Diseases Unit, Intemational Institute of Parasitology, 395A Hatfield Road, St Albans, Herts AL4 OXU, U.K. volatile emissions from freshly laid eggs were attractive to gravid flies, and gas chromatographic analysis of the volatile collections showed that this attractiveness was associated with the presence of two compounds. Although that study dealt only with one cytospecies, these compounds have also been found in the eggs or gravid ovaries of four other cytospecies within the S.damnosum species complex (McCall et al., 1997), suggesting that one pheromone may be responsible for the mediation of oviposition aggregation for all species within the complex.

Blackflies of the S.damnosum complex are the most important vectors of onchocerciasis in Africa, and are responsible for disease transmission in the majority of those African countries affected. Despite the success of the Onchocerciasis Control Programme (OCP) sustained over much of sub-Saharan west Africa over the past 20 years, more than 17 million people remain infected with Onchocerca volvulus in twenty-six African countries, with 118 million people still at risk of acquiring new infections (Anon., 
1995). Onchocerciasis control, by vector control and/or ivermectin distribution, is continuing within the OCP area and new control programmes are currently being developed in many other countries throughout west and central Africa. Regardless of the control method, routine entomological evaluation is essential in monitoring progress, and future programmes will depend upon regular and reliable blackfly sampling. In addition to its importance in the determination of vectorial capacity and transmission risk, vector monitoring is of special importance in onchocerciasis control, since certain members of the Simulium damnosum complex are capable of migrating across long distances into controlled areas, potentially reintroducing infections (Baker et al., 1990). In the absence of any effective alternative, all entomological monitoring is still carried out by the collection of biting female flies on human bait, over an $11 \mathrm{~h}$ period on selected days (Anon., 1995), a method which in addition to the ethical issues it raises, can be unreliable and inconsistent.

Attractant traps have never been used to monitor S.damnosum s.l. populations regularly, although a visually attractive oviposition trap has already been developed and has been shown to be effective in collecting blackflies (Bellec, 1976). Oviposition traps which collect eggs or gravid adult females have been used successfully in the monitoring of mosquito vector populations (Mogi et al., 1988; Reiter et al., 1986), and their effectiveness has been improved by the addition of attractive odours (Reiter $e t$ al., 1991). Gravid traps or ovitraps have the additional advantage in that a very high proportion of those insects trapped will be parous, thus reducing the time and cost of detecting infected individuals during subsequent dissection. Demonstration of the existence of an oviposition aggregation pheromone in $S$.damnosum s.l. renews the possibility of developing an odour-baited oviposition trap for routine population surveillance or possibly even control of Simulium damnosum s.l. We report here on progress towards chemical characterization of that pheromone.

\section{Materials and Methods}

Blackflies and study site. The study was carried out at the Onchocerciasis Control Programme (OCP) subsector base in Hohoe, Volta Region, Ghana, during May-July 1995. Wild female S.damnosum s.l. were collected as they landed on human bait near the village of Alavanyo Abehenease at Tsatsadu Falls $\left(00^{\circ} 23^{\prime} \mathrm{E}, 07^{\circ} 08^{\prime} \mathrm{N}\right)$, and returned to the laboratory. In the past, Simulium yahense and Simulium squamosum have both been recorded biting man at Tsatsadu Falls, with S.yahense the more abundant cytospecies (Cheke et al., 1992). An additional collection of blackflies was also made at the village of Hemang on the river Pra (15 July 1995) in Southern Ghana (01 ${ }^{\circ} 36^{\prime} \mathrm{W}$, $05^{\circ} 11 \mathrm{~N}$ ), where S.sanctipauli occurred (Wilson, 1994). The collected flies were bloodfed on man or pigs, and maintained in the laboratory for up to 5 days, using methods previously described (McCall et al., 1994). Samples of flies from each site were stored in alcohol for identification by morphometric means (Wilson et al., 1993).

Volatile collections. Previous studies on oviposition aggregation were made with Simulium leonense in Sierra Leone (McCall et al., 1994; McCall, 1995), and the fractions of ovary extract were prepared for bioassay from that species. However, increasing military unrest in Sierra Leone compelled the project to relocate in Ghana. To determine if the prepared S.leonense extracts would be suitable for bioassay with the blackfly species at Tsatsadu Falls, S.yahense, an analysis of the volatile emissions of the latter was first made for comparison with known volatile profiles of the former (McCall, 1995). Fresh egg volatiles were collected from eggs laid onto glass wool (cleaned in acetone and hexane and dried before use) within $30 \mathrm{~min}$ of oviposition. Volatiles were collected on filters packed with $25 \mathrm{mg}$ Super Q adsorbent (80100 mesh; Alltech, Carnforth, U.K.) in a closed glass system ( $300 \mathrm{ml}$ volume), at an airflow of $1 \mathrm{~V}$ min for $2 \mathrm{~h}$. Incoming air passed through a charcoal filter and molecular sieve before entering two parallel chambers containing the eggs or control, and exited through the Super $Q$ filters. All glass, teflon and brass surfaces in contact with the samples or moving air were rinsed with acetone and hexane before each use. Air flow in the system was balanced by a combined pump and vacuum, equalized in both parallel chambers with flowmeters and maintained at slight positive internal pressure (monitored by a simple manometer) to avoid contamination in the event of a leak occurring. The apparatus and procedures used for inducing S.damnosum s.l. to oviposit within this clean glass environment and the subsequent collection of egg volatiles have been described in detail by McCall (1995).

Super $Q$ filters were sealed with teflon tape following collection and stored at $0^{\circ} \mathrm{C}$ until analysed. The filters were rinsed with $200 \mu \mathrm{l}$ dichloromethane and $n$-hexadecane was added as an internal standard to a final concentration of $10 \mathrm{ng} / \mu \mathrm{l}$ in the volatile collection. Volatiles were analysed on an AI (AI Scientific, Cambridge, U.K.) model 93 gas chromatograph with a splitsplitless injector system $\left(220^{\circ} \mathrm{C}\right)$ and flame ionization detector $\left(250^{\circ} \mathrm{C}\right)$, and helium as the carrier gas on a fused silica column ( $30 \mathrm{~m} \times 0.32 \mathrm{~mm}$ i.d.) with a dimethylpolysiloxane film ( $1 \mu \mathrm{m}$; SPB-1, Supelco, Saffron Walden, U.K.), and $5 \mathrm{~m}$ guard column of deactivated fused silica $(0.32 \mathrm{~mm}$ id). Injections were made at $40^{\circ} \mathrm{C}$ in the splitless mode and split after $30 \mathrm{~s}$. The program maintained the initial temperature for $2 \mathrm{~min}$, followed by a ramp of $10^{\circ} \mathrm{C} / \mathrm{min}$ to $200^{\circ} \mathrm{C}$. Data were collected, analysed and stored with a Varian GC Star Workstation chromatographic data system.

Preparation of fractions. Fractions were prepared from ovaries of 400 S.leonense collected at the River Tabe in southern Sierra Leone $\left(11^{\circ} 44^{\prime} \mathrm{W}, 07^{\circ} 51^{\prime} \mathrm{N}\right)$ during February-April 1994. The flies were bloodfed on pigs and maintained for 3 days in the laboratory $\left(25-30^{\circ} \mathrm{C}\right)$ to allow egg maturation. Gravid ovaries were dissected and stored at $-20^{\circ} \mathrm{C}$ before extraction in hexane. Micropreparative collections and analysis of fractions obtained were made using a Hewlett-Packard (Avondale, Pa., U.S.A.) 5890 gas chromatograph, equipped with a cool on-column capillary injector and a flame ionization detector. The column ( $30 \mathrm{~m}$ long, $0.32 \mathrm{~mm}$ i.d.) was a bonded $100 \%$ methyl silicone column ( $5 \mu \mathrm{m}$ film thickness), with a $10 \mathrm{~m}$ long retention gap (Grob, 1982) of trimethylsilane deactivated fused silica. Helium was used as carrier gas at a linear flow rate of $18 \mathrm{~cm} / \mathrm{s}$. The temperature programme began at isothermal $60^{\circ} \mathrm{C}$ for $5 \mathrm{~min}$, followed by a $10^{\circ} \mathrm{C} /$ min increase to $200^{\circ} \mathrm{C}$.

Fractions were isolated by micro-preparative gas chromatography using the same conditions. The effluent from the capillary column was split with $2 \%$ routed to the detector and $98 \%$ collected in cooled glass capillary tubes (Brownlee \& Silverstein, 1968), which 


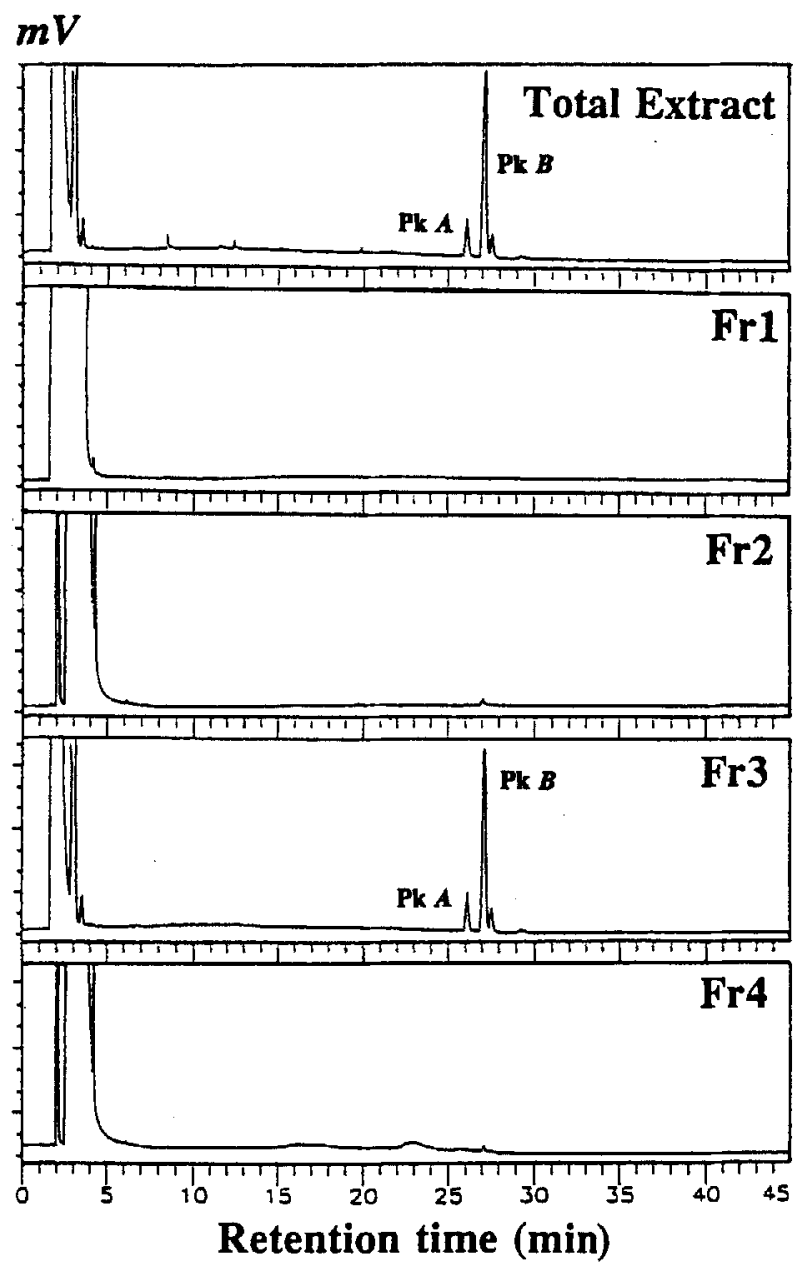

Fig. 1. Chromatograms of a total ovary extract of Simulium leonense, and the four fractions ( $\mathrm{Fr}$ ) isolated from it: Fr 1 (eluting at retention time 0-21 min), Fr $2(21-25 \mathrm{~min})$ Fr 3 (25-28 min), Fr 4 (28-45 min). Peaks $A$ and $B$ were known to be the only compounds consistently found emanating from freshly laid eggs, and were shown to be associated with egg atractiveness to gravid flies (McCall, 1995). Fractions were separated on a methyl silicone column ( $30 \mathrm{~m}$ long; $0.32 \mathrm{~mm}$ i.d.; $5 \mu \mathrm{m}$ thickness) with a $10 \mathrm{~m}$ retention gap, under conditions described in the text.

were rinsed in $100 \mu \mathrm{l}$ dichloromethane. Data were stored and analysed with a Nelson 4000 data system (P. E. Nelson, Cupertino, Calif., U.S.A.). Four fractions were prepared, as shown in Fig. 1. Peaks $A$ and $B$ were isolated in fraction 3 . The third peak visible in Fig. 1, eluting immediately after Peak B, was occasionally observed in egg extracts and volatiles during this and previous studies, but did not occur consistently in any of the species examined. As its presence in egg volatiles was not found to be necessary for attraction of eggs to gravid flies to occur (McCall, 1995), it was not considered in the present study.

For bioassays, fractions were diluted to a peak $B$ concentration equal to $5 \mathrm{ng} / \mu \mathrm{l}$. This was equivalent to $2.5 \mathrm{egg}$ batch hour equivalents of peak B and $1 \mathrm{egg}$ batch hour equivalent of peak $A$, as determined from the fresh egg volatile emissions of S.leonense, based on comparison at $G C$ analysis with the internal standard $n$-hexadecane ( 1 egg batch hour equivalent peak $A=0.4 \mathrm{ng}$, peak $\mathrm{B}=2 \mathrm{ng}$; McCall, 1995).

Bioassays. Techniques and equipment for inducing oviposition in Simulium damnosum s.l. and the bioassay procedure for measuring responses to oviposition attractants have been described previously by McCall et al. (1994). The protocol used in some of the experiments described here was modified slightly from that procedure to enable multiple choice bioassays to be performed. Bioassays were carried out in a white polystyrene chamber $(270 \times 270 \times 180 \mathrm{~cm}$ high), with net sides. Water pumped from a reservoir was split into a variable number of different outlets (see below) each of which dripped $(20 \mathrm{ml} / \mathrm{min}$ ) onto a substrate (nylon netting stretched taut over a glass funnel filled with glass wool) set into the floor of the chamber. The flies oviposited on the netting which was lit diffusely through the glass wool from beneath, at an intensity of 15-30 lux. The observer viewed the bioassay through the netting wall at the front of the chamber. A choice of substrate was counted only when a fly began to oviposit, and all flies were removed when they were observed at the initial stages of ovipositing; typically flies landed and immediately extended their terminalia beneath them onto the surface of the substrate, before starting the bobbing movement associated with egg deposition. All bioassays were carried out between 18.00 and 20.00 hours. A series of different bioassay experiments were performed as follows.

Two-choice bioassays. The four individual fractions were recombined in equal volumes, and their activity tested in a twochoice bioassay. This test examined whether the fractionated ovary extracts retained the activity of the previously tested untreated volatile collections (McCall, 1995). These tests were also necessary to determine if S.damnosum s.l. cytospecies from this region of Ghana would respond to extracts from Sierra Leonean S.leonense. The substrate was baited with $20 \mu \mathrm{l}$ recombined extract (equivalent to $12.5 \mathrm{egg}$ batch equivalents per hour) by evaporating in hexane onto a $2.5 \mathrm{~cm}^{2}$ square of filter paper (prewashed in acetone and hexane), suspended at $5 \mathrm{~mm}$ over the oviposition substrate. Control baits were treated with hexane. Twenty gravid flies were introduced and allowed $20 \mathrm{~min}$ to select a substrate for oviposition before removal from the chamber. The positions of the baited substrate and the control within the test chamber were reversed on alternate bioassays. All subsequent bioassays involving tests of single fractions and an appropriate control, were carried out using this procedure.

Multiple-choice bioassays. All four individual fractions were initially bioassayed simultaneously in a multiple choice variation of the above system. Oviposition substrates were arranged in a symmetrical circle around the centre point of the chamber floor, with substrates equidistant from each other. Substrates were baited with $20 \mu \mathrm{l}$ of each fraction (equivalent to $40 \mathrm{egg}$ batch hour equivalents) or control as described above. The relative positions of the fractions were assigned at random in each bioassay. Twentyfive gravid flies were introduced into the chamber with an aspirator and allowed $30 \mathrm{~min}$ to select an oviposition substrate.

Following this first series of bioassays, those fractions which demonstrated attraction were retested in multiple- choice bioassays. Since the number was reduced, substrates were rearranged in a symmetrical array about the centre of the chamber equidistant from each other, and relative positions assigned at random in each bioassay. 


\section{Results}

\section{Cytospecies identification}

All thirty-six individuals examined from Tsatsadu Falls were identified by multivariate morphometric analysis as Simulium yahense Vajime \& Dunbar, and twenty-nine individuals examined from Hemang were identified as Simulium sanctipauli s.l. Vajime \& Dunbar.

\section{Egg volatile analysis}

Volatiles were collected and analysed from eighteen egg batches of S.yahense from Tsatsadu Falls, in two separate collections. A typical GC profile from fresh egg volatiles of S.yahense is shown in Fig. 2. The profile was identical to that previously recorded from S.leonense in Sierra Leone, with two major peaks occurring at retention times of $21.85 \mathrm{~min}$ (peak A) and $22.35 \mathrm{~min}$ (peak B) occurring in both S.yahense volatile collections. The emission rates for both collections were 0.1 and $0.15 \mathrm{ng} / \mathrm{egg}$-batch/hour (peak A), and 2.8 and $0.46 \mathrm{ng} / \mathrm{egg}$-batch/hour (peak B) (ratios of $1: 28$ and $1: 3$ ) respectively, as determined by comparison with the internal standard.

\section{Bioassays}

In the combined results of all the bioassays, 34\% (228/670) of all blackflies tested responded by landing on a substrate and initiating oviposition behaviour. Of 135 of these landings which were timed, $111(82 \%)$ occurred within $10 \mathrm{~min}$ of entering the chamber, with the remainder occurring between 10 and $20 \mathrm{~min}$. No further ovipositions occurred until observation finished at $30 \mathrm{~min}$.

Two-choice bioassay of recombined fractions. A total of $41.7 \%$ $(50 / 120)$ of blackflies responded in trials comparing responses to a substrate baited with recombined fractions and a control. In six trials, thirty three (66\%) blackflies selected substrates baited with recombined volatile fractions, as compared with seventeen (34\%) selecting controls, a difference which was significant $\left(\chi^{2}=4.5,1 \mathrm{df}, P<0.05\right)$.

Multiple-choice bioassay of individual fractions. A total of ten bioassays were conducted to compare the attractiveness of each of the four fractions and a control in a five-choice bioassay. The results are presented in Fig. 3. A total of $77 / 250$ (31\%) of blackflies responded in the trials, of which $26(34 \%)$ chose the substrate baited with fraction 3 . Only this substrate attracted significantly more blackflies than the control or other substrates $\left(\chi^{2}=12.4,4 \mathrm{df}, P<0.02\right)$, and it was in fact the most attractive in $6 / 10$ trials. Fraction 4 was also attractive, with $18 / 77(23.4 \%)$ landings. Thus fractions 3 and 4 together accounted for $57 \%$ of all responses in the trials. Since this suggested that both fractions 3 and 4 may have had a role in attraction, a second series of multiple-choice bioassays was carried out.

Multiple-choice bioassay of fractions 3 and 4 . The results of bioassays which compared the attractiveness of fractions 3 and 4 separately and in combination are shown in Fig. 4. In total, 150 flies were tested, of which fifty-four (36\%) responded. In all six trials, substrates baited with fraction 3 alone or with the combination of fractions 3 and 4 were the most attractive, with $70 \%$ (38/54) of all landings on both. Responses to either bait were significantly different from those to substrates baited with fraction 4 alone or the control $\left(\chi^{2}=9.26,3 \mathrm{df}, P<0.05\right)$. The addition of

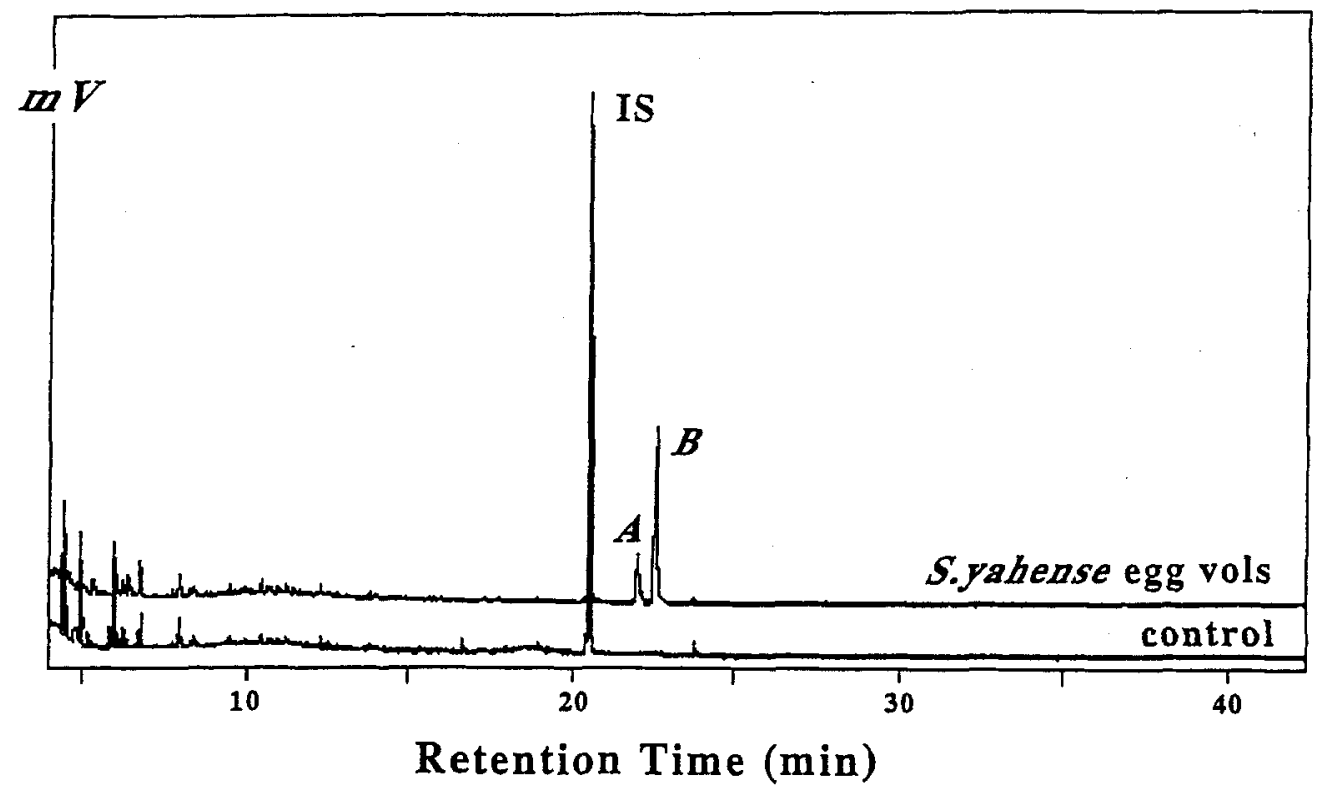

Fig. 2. Chromatogram of the volatiles released from eggs of S.yahense (ten batches), with a system blank (control) collected in parallel, following volatile collection at a flow rate of $1 \mathrm{l} / \mathrm{min}$ for $2 \mathrm{~h}$. IS (internal standard) is equivalent to $5 \mathrm{ng}$ of the internal standard $n$-hexadecane. The retention times and quantities of each peak are $21.85 \mathrm{~min}, 0.06 \mathrm{ng}$ (peak A), and $22.35 \mathrm{~min}, 0.23 \mathrm{ng}$ (peak B), calculated by comparison with the internal standard. The chromatogram was obtained following injection of $0.5 \mu \mathrm{l}$ onto a $30 \mathrm{~m}$ dimethylpolysiloxane column $(0.32 \mathrm{~mm}$ i.d., $1 \mu \mathrm{m}$ thickness) with a $5 \mathrm{~m}$ guard column, under conditions described in the text. 


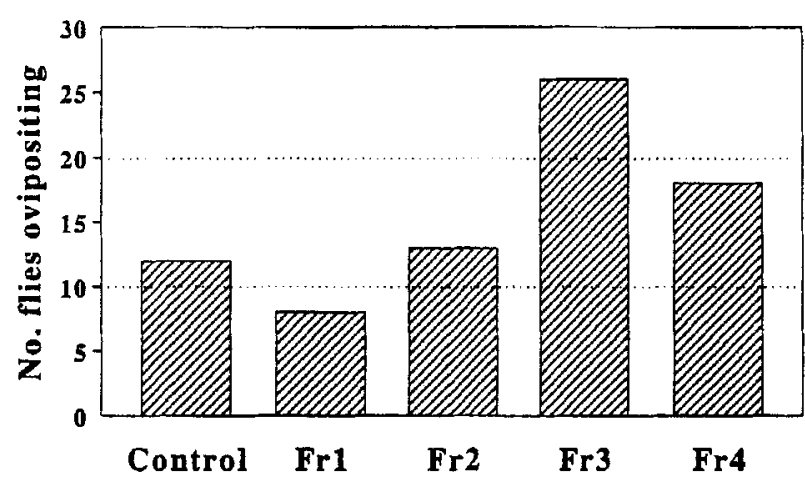

Fig. 3. Responses of S.yahense to a choice of five oviposition substrates, four baited with a different ovary extract fraction (Fr), and a fifth with a control (hexane only), showing the numbers of flies selecting each substrate for oviposition. In total, 250 flies were tested in ten trials, of which seventy-seven $(31 \%)$ responded, and $34 \%$ of these selected the substrate baited with fraction 3 , a result which was significant $\left(\chi^{2}=12.4\right.$, $4 \mathrm{df}, P<0.02$ ).

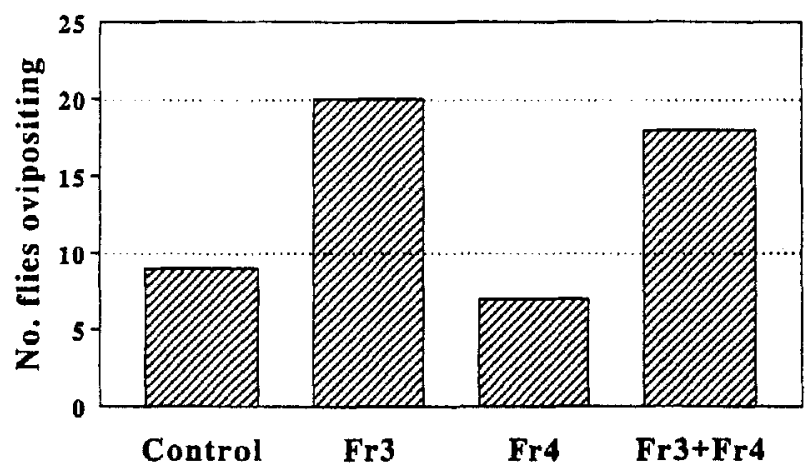

Fig. 4. Responses of S.yahense to a choice of three oviposition substrates, baited with fraction (Fr) 3, fraction 4, fraction 3 and 4 combined, and a control (hexane only), showing the numbers of flies selecting each substrate for oviposition. In six trials, 150 flies were tested, of which fifty-four (36\%) responded. $70 \%$ (38/54) of all choices were made on substrates baited with Fr 3 or on the combination of Fr 3 and Fr 4, a result which was significant $\left(\chi^{2}=9.26,3 \mathrm{df}, P<0.05\right)$.

fraction 4 to fraction 3 did not appear to increase the attractiveness of the latter, suggesting that in this bioassay, fraction 3 alone was sufficient to elicit a response.

Two-choice bioassay of fraction 3. A total of $39.2 \%$ (47/120) of flies responded in trials comparing the response to substrates baited with fraction 3 alone or control. In six trials there was no difference between the numbers of blackflies selecting substrates baited with fraction $3(24 / 47,51 \%)$ as compared with the control $(32 / 47,49 \%)$. Five bioassays were also carried out with S.sanctipauli from Hemang, but only one fly responded, selecting the substrate baited with fraction 3 .

Bioassay response rates. The overall response rates in each of the bioassays, as measured by the numbers of flies selecting either oviposition substrate, were not significantly different between the trials with fraction 3 alone $(47 / 120,39.2 \%)$ and trials with recombined fractions $(50 / 120,42 \%)$, or in the multiple-choice trials with all fractions $(77 / 250,31 \%)$ or with fractions 3 and 4 $(47 / 150,31 \%)(P>0.05$, Mann-Whitney test).

\section{Discussion}

Earlier studies on pheromone-mediated oviposition aggregation in S.damnosum s.l. demonstrated that only two major peaks (peaks $A$ and B, Fig. 1) occurred consistently in volatile collections and ovary extracts, in all species studied within this species complex, and that those peaks were associated with attraction of site seeking ovipositing flies (McCall, 1995; McCall et al., 1997). In the multiple choice bioassay results presented here, the fraction containing these two compounds, fraction 3 , attracted a significantly greater number of ovipositions than any other fraction, confirming the role of these two compounds as constituents of the oviposition aggregation pheromone. However, the failure of fraction 3 to elicit a significant response when presented as the sole bait in a twochoice bioassay suggests that other attractants are also necessary to complete the response. Ovipositions occurred preferentially on substrates baited with fraction 3 only when other fractions, in particular fraction 4 , were also present. In fact it was not necessary for fraction 4 to be combined with fraction 3 in order to elicit a response. In the four-way bioassay, the response to substrates baited with fraction 3 alone were comparable to those on substrates baited with the combined fractions 3 and 4 . Thus, only the presence of fraction 4 in the vicinity of fraction 3 was necessary to elicit a response to fraction 3 . Whether these could act in tandem, or in a specific behavioural sequence remains unknown. Determination of the contents of fraction 4 may be problematic as the chromatograms do not indicate the presence of any detectable peaks. It is of interest that no variation in overall response rate occurred in any of the bioassay procedures. Previously (McCall, 1995), in bioassays using baits with significantly reduced concentrations of peaks $A$ and $B$, lower overall responses were observed. However, in the experiments reported here, it would seem that even the presence of fraction 3 within the bioassay chamber mediated an oviposition response. Further bioassays are planned.

The isolated fractions of ovary extract retained their attractiveness for gravid blackflies in bioassay. Collected volatiles from fresh eggs were also shown to be effective in attracting gravid flies (McCall, 1995), demonstrating that the active components of the pheromone are stable and can be isolated, stored and manipulated. In fact the response rate of S.yahense in these experiments $(34 \%)$ was higher than previously recorded for S.leonense (mean response of $23 \%$ to whole eggs, McCall et al., 1994; mean response of $12 \%$ to collected volatiles, McCall, 1995). This suggests that this species is more suitable for laboratory studies than S.leonense. Conversely, the failure of S.sanctipauli to respond in the bioassays is more likely a result of its behaviour in the laboratory than any indication that pheromone mediation is not important in oviposition behaviour. The volatile emissions from the eggs of S.sanctipauli (McCall et al., 1997) are similar to volatile emissions and ovary extracts from S.leonense (McCall, 1995 ) and $S$. yahense. Moreover, in addition to these three species, S.squamosum from Cameroon and S.sirbanum from Ghana also contain peaks A and B within gravid ovaries (McCall, et al., 1997), suggesting that the pheromone may be similar in all species. This 
is supported by the fact that the extracts used in the present series of bioassays were prepared from Sierra Leonean S.leonense but used effectively to attract Ghanaian $S$.yahense. It is not uncommon to find mixtures of different cytospecies in larval samples from West African rivers (e.g. Post \& Crosskey, 1985), and it is possible that such larvae could originate from the same mixed-species egg mass. Traps with oviposition aggregation pheromone baits might therefore be effective against all of the members of the S.damnosum complex across West Africa. Moreover, it is likely that this pheromone is the only chemical cue involved in the mediation of oviposition in $S$. damnosum s.1. Gravid female flies do not themselves emit any compounds during oviposition (McCall, 1995), and since blackflies in general breed in clean, highly oxygenated flowing waters, environmental attractants are unlikely to be involved in attraction to oviposition sites. This is an advantage when discussing the possibility of developing an odour-baited trap. In Culex quinquefasciatus the oviposition aggregation pheromone was found to be secondary to environmental odours as an attractant, rendering the pheromone less effective in practice (Otieno et al., 1988). Similarly, the oviposition aggregation pheromone of Lutzomyia longipalpis requires the presence of a number of oviposition site kairomones derived from decaying organic material, in order to elicit a full response (Dougherty et al., 1993). Such problems should not be expected to occur with the $S$. damnosum s.l. pheromone.

Development of a trap based on this pheromone as an odour bait will depend on many additional factors. The range of thepheromone and its effectiveness in a natural environment have yet to be determined. The structure of traps would also need to be investigated. Simple visual traps for the collection of ovipositing S.damnosum s.l. have already been used to a limited extent in Africa (Bellec, 1976), but might need modification. It is known that the selection of oviposition substrates by S.damnosum s.l. is influenced by colour, with paler substrates being preferred (Elsen \& Hebrard, 1977; Walsh, 1984). The potential of pheromonebaited traps for monitoring or control has yet to be realized with insects of importance in human or animal disease. Recent interest in this field has led to a number of studies on oviposition aggregation pheromones in Glossinidae, Psychodidae and Culicidae as well as in Simuliidae, though none has yet been developed for routine use (McCall \& Cameron,1995).

In conclusion, this study has demonstrated that the oviposition pheromone of S.damnosum s.l. is stable following fractionation. The pheromone consists of a major attractant fraction, fraction 3, comprising two major compounds, which have previously been denoted peaks $A$ and $B$. However, this fraction was effective only when a second fraction, fraction 4 , was also presented in the bioassay chamber. Attraction to substrates baited with fraction 3 in the presence of fraction 4 occurred even when both were presented from separate point sources. Future work will identify peaks $A$ and $B$, and determine the role of fraction 4 and/or other cues in the attraction of gravid blackflies.

\section{Acknowledgments}

We are especially grateful to the Director Dr Y. Dadzie, and to Messrs Seketeli, S. Sowah and A. Adjah of the Onchocerciasis Control Programme for the use of laboratory facilities at the subsector office, Hohoe, Volta Region, Ghana, and we thank the Director of the Noguchi Memorial Institute for Medical Research, Professor F. Nkrumah, for support within Ghana. We are also indebted to Togbe Kwaku Kunde IV, chief of Alavanyo Abehenease, for permission to work at Tsatsadu Falls, and to Daniel Boakye, Hendrik Jan Megens, Perry Yao Akolor, Fliku Sampson Adzewoda and Alex K. Tutu for field assistance. P.J.M. was supported by The Wellcome Trust, London (grant no. 043862/Z/95/Z).

\section{References}

Anon. (1995) Onchocerciasis and its control. Report of a WHO expert committee on onchocerciasis control. WHO Technical Report Series, no. 852 .

Baker, R.H.A., Guillet, P., Sékétéli, A., Poudiougo, P., Boakye, D., Wilson, M.D. \& Bissan, Y. (1990) Progress in controlling the reinvasion of windborne vectors into the western area of the Onchocerciasis Control Programme in West Africa. Philosophical Transactions of the Royal Society of London B, 328, 731-750.

Bellec, C. (1976) Capture d'adultes de Simulium damnosum Theobald, 1903 (Diptera: Simuliidae) à l'àde de plaques d'aluminium en Afrique de l'Ouest. Cahiers ORSTOM (Entomologie Médicale et Parasitologie), 14, 209-217.

Brownlee, R.G. \& Silverstein, R.M. (1968) A micro-preparative gas chromatograph and a modified carbon skeleton determinator. Analytical Chemistry, 40, 2077-2079.

Cheke, R.A., Avissey, H.S.K., Sowah, S.A., Walsh, J.F. \& Garms, R. (1992) The vectorial efficiency of Simulium yahense populations in south-eastern Ghana. Tropical Medicine and Parasitology, 43, 62-64.

Crosskey, R.W. (1990) The Natural History of Blackflies. John Wiley \& Sons, London.

Dougherty, M.J., Hamilton, J.G.C. \& Ward, R.D. (1993) Semiochemical mediation of oviposition by the phlebotomine sandfly Lutzomyia longipalpis. Medical and Veterinary Entomology, 7, 219-224.

Elsen, P. \& Hébrard, G. (1977) Méthodes d'échantillonage des populations preimaginales de Simulium damnosum Theobald 1903 (Diptera: Simuliidae) en Afrique de l'Ouest. II. Observations sur le choix des coleurs, l'évolution de peuplement et la tépartition horizontale au moyen de rubans en plastique. Tropenmedizin und Parasitologie, 28, 471477.

Grob, J.J. (1982) Band broadening in space and the retention gap in capillary gas chromatography. Joumal of Chromatography, 237, 15-23.

McCall, P.J. (1995) Oviposition pheromone in the Simulium damnosum complex. Medical and Veterinary Entomology, 9, 101-108.

McCall, P.J. \& Cameron, M.M. (1995) Oviposition pheromones in insect vectors. Parasitology Today, 11, 352-355.

McCall, PJ., Trees, A.J., Walsh, J.F. \& Molyneux, D.H. (1994) Aggregated oviposition in the Simulium damnosum complex is mediated by eggs in a laboratory bioassay. Medical and Veterinary Entomology, 8, 7680.

McCall, P.J., Wilson, M.D., Dueben, B.D., Bronsvoort, B.M. de Clare \& Heath, R.R. (1997) Similarity in oviposition aggregation pheromone composition within the Simulium damnosum (Diptera: Simuliidae) species complex. Bulletin of Entomological Research, 87, in press.

Mogi, M., Khamboonruang, C, Choochote, W. \& Suwanpanit, P. (1988) Ovitrap surveys of dengue vector mosquitoes in Chiang Mai, northem Thailand: seasonal shifts in relative abundance of Aedes albopictus and Ae.aegypti. Medical and Veterinary Entomology, 2, 319-324.

Otieno, W.A., Onyango, T.O., Pile, M.M., Laurence, B.R., Dawson, G.W., Wadhams, L.J. \& Pickett, J.A. (1988) A field trial of the synthetic oviposition pheromone with Culex quinquefasciatus Say (Diptera: Culicidae) in Kenya. Bulletin of Entomological Research, 78, 463-478. 
Post, R.J. \& Crosskey, R.W. (1985) The distribution of the Simulium damnosum complex in Sierra Leone and its relation to onchocerciasis. Annals of Tropical Medicine and Parasitology, 79, 169-194.

Reiter, P., Jakob, W.L., Francy, D.B. \& Mullenix, J.B. (1986) Evaluation of the CDC gravid trap for the surveillance of St Louis encephalitis vectors in Memphis, Tennessee. Journal of the American Mosquito Control Association, 2, 209-211.

Reiter, P., Amador, M.A. \& Colon, N. (1991) Enhancement of the CDC ovitrap with hay infusions for daily monitoring of Aedes aegypti populations. Joumal of the American Mosquito Control Association, 7, 5255.

Walsh, J.F. (1984) Aspects of the biology and control of Simulium damno- sum s.l. (Diptera: Simuliidae) in West Africa. Ph.D. thesis, University of Salford.

Wilson, M.D. (1994) Morphological and molecular methods for the identification of adult female Simulium damnosum species complex vectors of onchocerciasis. Ph.D. thesis, University of Salford.

Wilson, M.D., Post, R.J. Gomulski, L.M. (1993) Multivariate morphotaxonomy in the identification of adult females of the Simulium damnosum Theobald complex (Diptera: Simuliidae) in the Onchocerciasis Control Programme area of West Africa. Annals of Tropical Medicine and Parasitology, 87, 65-82.

Accepted 2 June 1997 